\title{
Drag reduction by combination of flow control using inlet disturbance body and plasma actuator on cylinder model
}

\author{
Budiarso $^{1}$, Harinaldi ${ }^{1}$, E. A. Kosasih $^{1}$, R. F. Karim ${ }^{2}$ and J. Julian ${ }^{2, *}$ \\ ${ }^{1}$ Department of Mechanical Engineering, Faculty of Engineering \\ Universitas Indonesia, Kampus Baru UI Depok 16424, INDONESIA \\ Phone: +6094246239; Fax: +609424222 \\ "Email: james.julian@ui.ac.id \\ ${ }^{2}$ Fluid Mechanics Laboratory, Faculty of Engineering \\ Universitas Indonesia, Kampus Baru UI Depok 16424, INDONESIA
}

\begin{abstract}
Flow past a cylinder is one of the things that is very applicable in everyday life. But behind those facts, there is a problem in it namely the drag force which is adverse and needs to be reduced. This research was conducted to find solutions to reduce drag by using a mix of passive flow control of inlet disturbance body and active flow control from plasma actuators. This research uses a test model in the form of a cylinder of a diameter of $120 \mathrm{~mm}$ with Reynolds Number 15000, 41000, 62000 and was expected to reduce drag after a given combination of flow control. From the results shown, either inlet disturbance of body and plasma actuators as well as a combination of both the flow of control is capable of performing the reduction coefficient of drag up to 70,22\% on a variation of the Reynolds Number 62000.
\end{abstract}

Keywords: Cylinder; Drag Coefficient; Flow Control; Inlet Disturbance Body; Plasma Actuator.

\section{INTRODUCTION}

Fluid flow is a phenomenon that is so fundamental in our daily life. Fluid flow which are generally divided into internal and external flow, going on around us all the time. Especially external flow, which happens in our body movement that is actually a phenomenon of fluid flow (the external flow) passing through an object. The related research of the flow passing through the object especially one of which is flow past a cylinder began to be repeatedly conducted. Research on the flow past through cylinders is an important research and presents so many challenges in a world of fluid mechanics [1]. This certainly cannot be separated from the fact there are so many application of flow past a cylinder such as the pillars of the offshore buildings, towers, chimneys, heat exchanger pipe, as well as the loads on transportations $[17,18]$.

However, behind that fact there is a problem, the existence of a drag force that affects the efficiency of fuel use and the generated speed of transportations as well as the effect on the level of stability and safety on construction aspect $[2,14]$. Drag force is also one of the load that affect the fatigue limit of a building [3]. So from that, we need to reduce drag. 
There is a method to resolve the issue, namely the flow control. Flow control is an ability that can be used to manipulate the flow of fluid $[4,21]$. The flow needs to be controlled because of flow control has an important role to get the desired effect such as the drag reduction, lift enhancement, and eliminate unwanted effects such as vortex, vibration, and the separation of the flow $[15,16]$. So to control the flow through the bluff body, many researchers tried to apply a wide range of flow control method, either passively or actively $[5]$.

Passive flow control doesn't need external energy and tend to modify the geometry of the object to manipulate streams, such as placing an object of bullies at the upstream of the main object or often called inlet disturbance of body. Active flow control is the control flow that uses additional energy to manipulate streams such as using plasma actuators to utilize the induced air properties to manipulate the electricity flow flowing $[6,20]$.

Research in drag reduction on the flow past a cylinder with inlet disturbance body is done by varying the sizes and distances of the disturbance rod. The disturbance rod is used in the form of a cylinder with a diameter of 0.1 diameter main cylinder that is placed at a distance of 1.75 length diameter main cylinder [7]. Similar studies are also carried out by varying the bluff body in front of the main cylinder with various configurations of a cutting angle a rod in the form of a profile I [8]. The results obtained from previous research using the inlet disturbance body indicate that this method is able to reduce drag effectively at high Reynolds Number, but less effective at low Reynolds Number. Inlet Disturbance Body was intended to create separation delay which passes through the cylinder and makes the flow more turbulent and have greater momentum, so when conditioned at low Reynolds Number, the momentum which given was not as big as on high Reynolds Number [9]. Research on the plasma actuators is performed using 3 electrodes on the cylinder to generate the plasma. The results of this study showed a decrease in drag by up to 25\% [10]. Plasma actuators research is also done to look at the influence of electrode placement on the test object with 13 placement configurations against the distribution of pressure and also the lift and drag force [19]. This research concluded that variations in the placement of the electrodes effect the resulting drag force where the plasma will be more effective when the electrodes were placed at the point close to the separation point [11].

Plasma is able to reduce drag by performing separation delay by means of giving momentum flow using electrical induction ionize the air flow. Plasma has advantages like reliability, easy installation and simple, and inexpensive cost. In the event of a reduction in drag, plasma is different with inlet disturbance body i.e. plasma is effective in doing drag reduction at low flow velocities, and less effective at high flow velocities.

While the research of having the inlet disturbance body and plasma actuator in each separate field has been done, the combination of both of them is still untouched. Both inlet disturbance of body as well as plasma, each has its advantages and disadvantages as well as the conditions effective in the reduction of drag. This research will try to combine the two methods to cover each owned disadvantage so that will hopefully produce a more significant drag reduction in the condition of a cylinder with a diameter of $120 \mathrm{~mm}$ and in Reynolds Number 15000, 41000, 62000 . 


\section{EXPERIMENTAL SETUP}

Experimental setup of this research involves multiple research devices and testing models. There are 4 main configurations in this study i.e., single cylinder, cylinder with rod without plasma, plasma, single cylinder with plasma and cylinder with rod and plasma with Reynolds Number 15000, 41000, and 62000. In order to acquire such Reynolds Numbers, the freestream was set to $1.8 \mathrm{~m} / \mathrm{s} ; 5 \mathrm{~m} / \mathrm{s}$; and $7.55 \mathrm{~m} / \mathrm{s}$ which measured using the hotwire anemometer.

\section{Model}

This study uses two main parts of model test, the main cylinder model which electrodes were applied and cylinder rod as inlet disturbance body. The main cylinder use hollow acrylic material with outer diameter (D) $120 \mathrm{~mm}$, length $200 \mathrm{~mm}$, and $3 \mathrm{~mm}$ in thick, as shown in Figure 1 (a) and Figure 2 for the detail configuration of the electrodes. A pair of electrodes made of copper sheet $10 \mathrm{~mm}$ wide with a thickness $0.05 \mathrm{~mm}$ respectively in the position angle of the 1050 and 2550 relative to 00 point at the upstream of the main cylinder. The rod use cylindrical acrylic material with the outer diameter (d) $12 \mathrm{~mm}(0.1 \mathrm{D})$ and a length of $300 \mathrm{~mm}$ which is positioned in front of the main cylinder with the distance of $\mathbf{L}$ (distance between the both center of the object) $210 \mathrm{~mm}(1.75 \mathrm{D})$, as shown on Figure 1 (b). While $\mathbf{U}$ being the magnitude and the direction of the freestream flow.

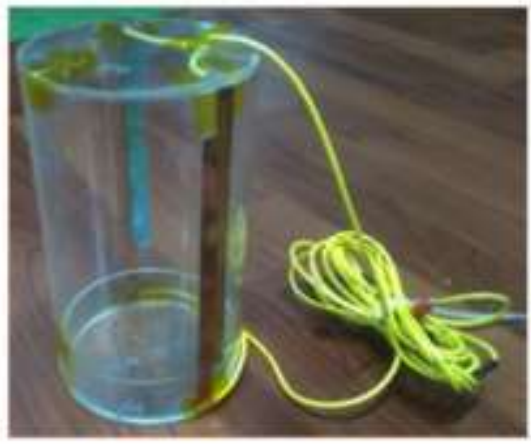

(a)

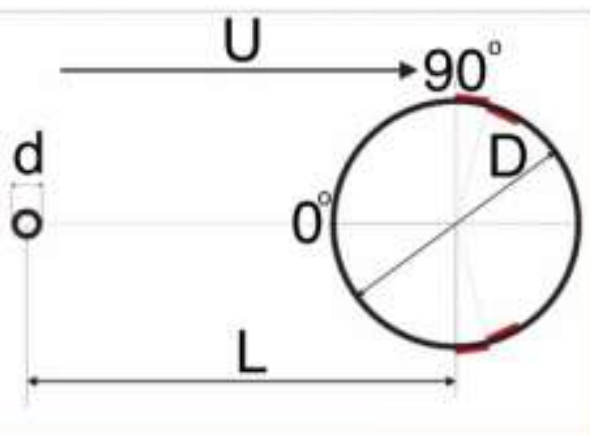

(b)

Figure 1. (a) Testing model (b) Flow geometry 


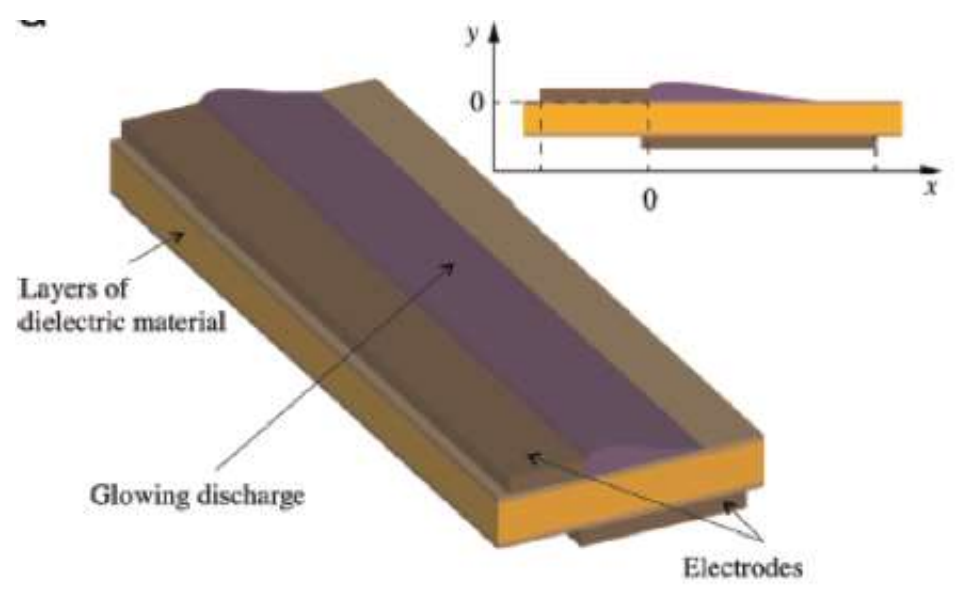

Figure 2. Schematic of Plasma Actuator [12]

\section{Experimental Devices}

In this study two major research devices were used, testing devices and plasma generation devices. As for the devices shown in the figure 3.

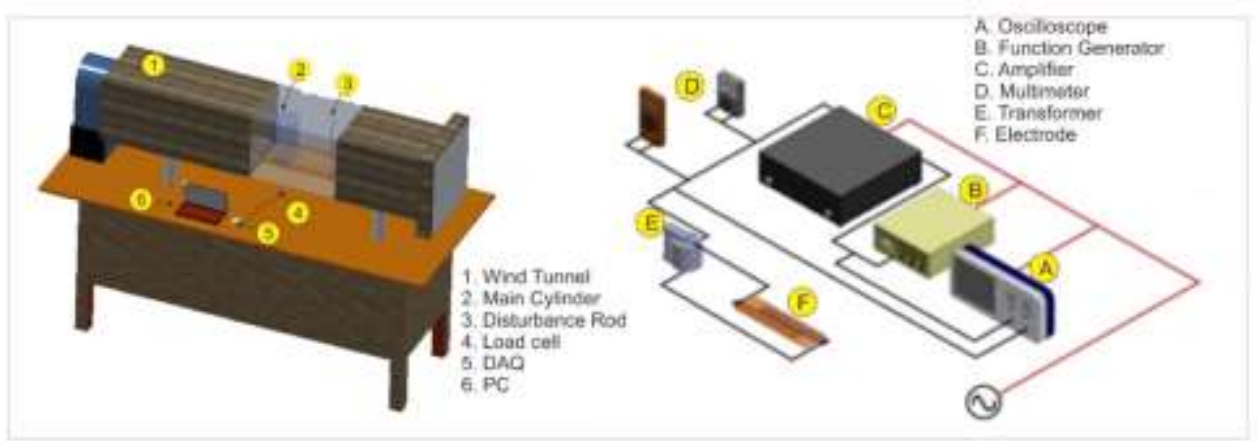

(a)

(b)

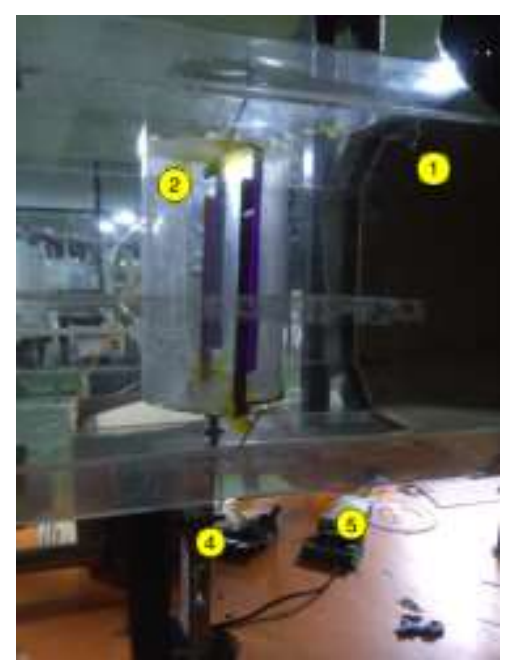

(c)

Figure 3. (a) Schematic of Experimental Setup; (b) Schematic of Plasma generation devices [13] (c) Real testing kit 
The testing device is in charge for the process of testing against the model and data retrieval. The data as drag force is taken by the load cell or strain gauge that changes the force from that flow into an analog electrical signal. To allow the computer to be able to read the incoming signal modulation, the analog signal into a digital signal device was being used.

Plasma generation devices served to generate the plasma as a method of flow control. Electricity from the source will be conditioned by the function generator and monitored using an oscilloscope. Electricity output function generator subsequently continues towards amplifiers and transformers to get the desired conditions for generating plasma on the electrodes.

\section{RESULTS AND DISCUSSION}

In Figure 4 is shown the resulting drag force using the load cell on the single-cylinder configuration and using rod. Of their respective graphs, the value shown is directly proportional to the Reynolds Number is given. The larger value of Reynolds Number, the larger drag force is generated. Graph (b) shows the value of drag force is relatively lower than the graph (a), especially at high Reynolds number condition. This shows the existence of the barrier rod was able to reduce the resulting drag force. In each graph there is also a difference between drag force on the conditions of plasma off and plasma on, where the resulting drag force values on the condition of the plasma turns on relatively lower than on the condition of the plasma does not light up at all the variations of the Reynolds number. This means the plasma was able to reduce the value of the resulting drag force.

The line graph in Figure 4 are likely to be bumpy and volatile, especially when the plasma was active. This is because the process of measurement data, the flow of air that hit test model makes it vibrates due to turbulence generated flow. The presence of plasma to make data becomes more volatile, is caused when air flow, induces plasma become garbled so that the load cell data which obtained also disturbed.

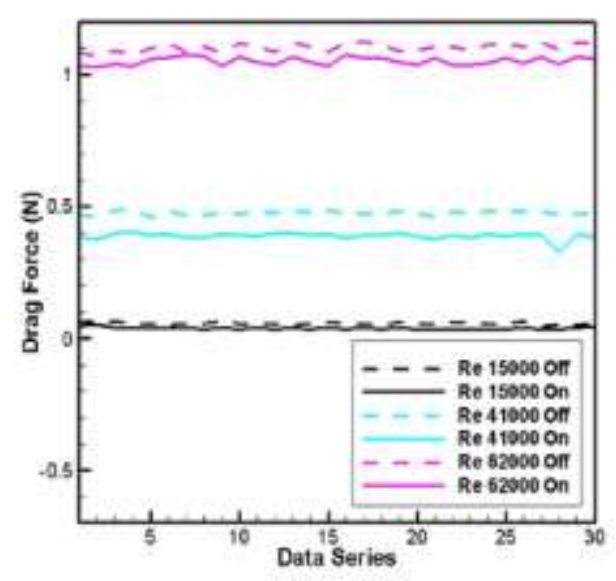

(a)

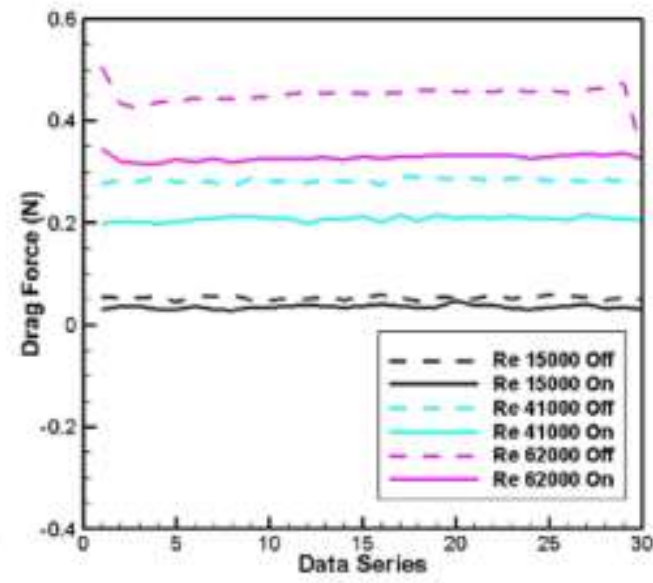

(b)

Figure 4. Drag force (a) Single cylinder; (b) Cylinder with Rod 
The Drag force data which has been measured, can be converted into the form of nondimensional number as coefficient of Drag $\left(C_{D}\right)$ by using the following formula.

$$
C_{D}=\frac{F_{D}}{\frac{1}{2} \rho U^{2} A}
$$

Where $F_{D}$ is the drag force, $\rho$ is the density of the air, $U$ is free stream velocity, and $A$ is the frontal area.

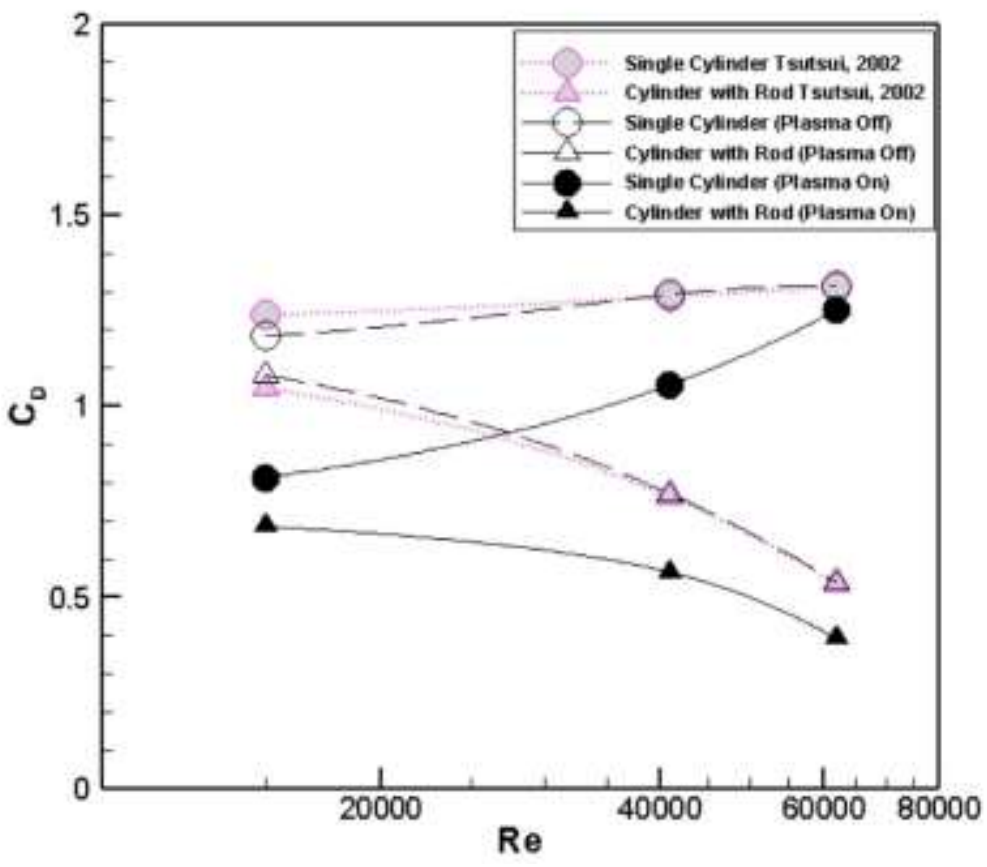

Figure 5. Correlation drag coefficient vs Reynolds Number

Figure 5 shows the value of the coefficient of drag from the 4 configurations. The drag coefficient value becomes lower when given control flow using either inlet disturbance body as well as plasma actuators, as well as combinations of the two. Each control flow features different trends and has different effective area of Reynolds Number in an attempt to give effect on the value of the drag coefficient. The drag coefficient on the configuration of the cylinder with rod without the plasma indicates the lowest value on the Reynolds Number 62000 (highest Reynolds number). This configuration is less effective on the low Reynolds Number. This is due to the workings of the use of this rod is uses the magnitude of the momentum that was generated. Flow with the high 6 Reynolds number tends to have a relatively greater momentum so that it is able to do separation delay. Separation delay would cause drag force produced relatively lower [9].

The drag coefficient on the configuration using plasma shows the lowest value at the lowest Reynolds number (15000). This configuration is less effective on the high Reynolds number. Higher Reynolds number also has a relatively higher flow velocity. The high flow velocity causing air ionization process by plasma actuator less effective so it gives effect in 
the reduction of drag has become less optimum. On the configuration of the combination flow control, trends that are showed by this Setup is similar with the trend shown by cylinder with rod without the plasma configuration but with a lower coefficient value. It shows on the configuration and the variation of this research the effects of inlet disturbance body is larger than the effect of plasma actuators. This can be caused the plasma that generated is small, or it can also be caused from the condition with Reynolds number used is more supportive of inlet disturbance body to perform the drag reduction.

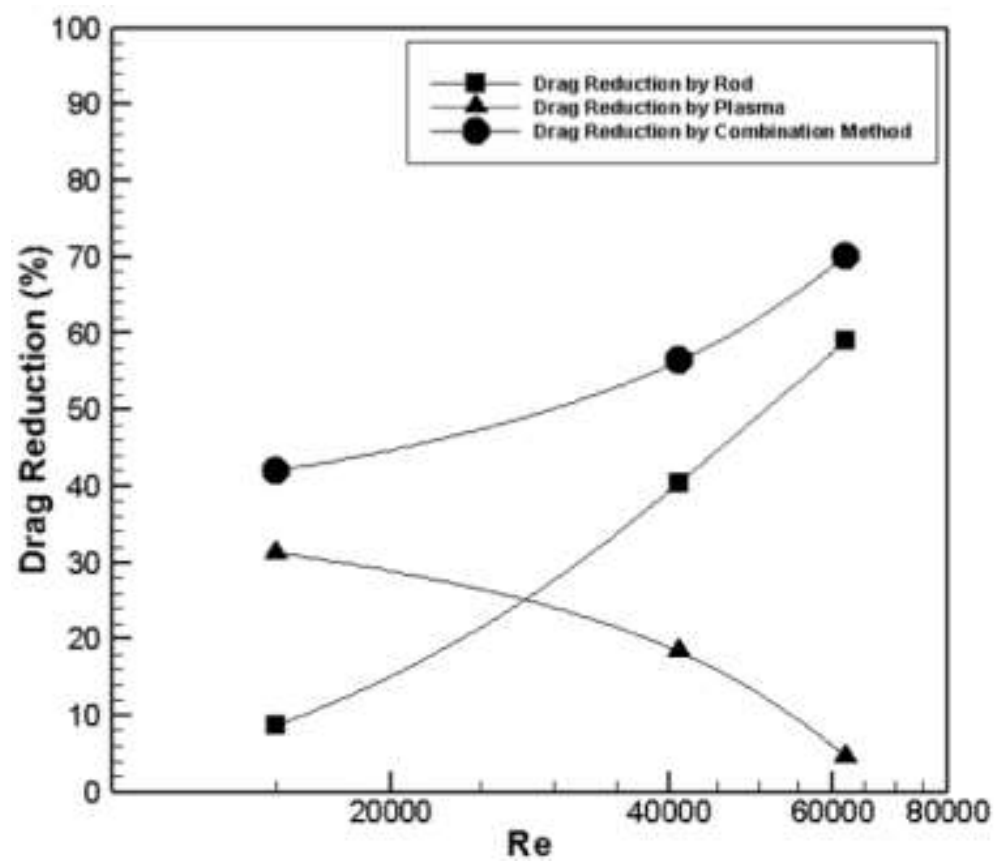

Figure 6. Correlation drag coefficient vs Reynolds Number

Figure 6 shows the graph of drag reduction conducted by each of the flow control. From the graphs shown, can be drawn a fact that each flow control methods have an effective Reynolds Number for drag reduction. Inlet disturbance of body more effective in high Reynolds Number that is on the Reynolds number 62000 with percentage of drag reduction reached $59.13 \%$, whereas plasma actuators more effective at low Reynolds Number (15000) 7 reached $31.24 \%$.

From the resulting data, it can be seen that plasma will have the capability of reducing drag force which is more dominant on the Reynolds Number below 25000, while the Reynolds number above 25000 inlet disturbance body will be more dominant to drag reduction. So for the application itself, if the flow rate is relatively low the use of plasma can be the right solution, while in relatively high flow velocities can be used with inlet disturbance body. The combined effect of both methods for the three variations of the Reynolds Number showed an ascending trend of drag reduction. Best drag reduction was achieved in the configuration of the cylinder with inlet disturbance body and plasma on Reynolds Number 62000 i.e. achieve $70.22 \%$. 


\section{CONCLUSIONS}

Both inlet disturbance body as well as plasma actuators, has proven capable of reducing drag in the condition of Reynolds Number 15000, 41000, and 62000. The best performance is reached in 59.13\% (Inlet disturbance body) at highest Reynolds Number (Re 62000) and $31.24 \%$ (plasma actuator) at the lowest Reynolds Number (Re 15000) respectively. The merging of the two methods of flow control also proved to be able to amplify the efforts of drag reduction with the best value $70,22 \%$ at the Reynolds Number of 62000 .

\section{REFERENCES}

[1] Bouak, F., \& Lemay, J. Passive control of the aerodynamic forces acting on a circular cylinder. Experimental Thermal and Fluid Science 1998;16(1);112-121.

[2] Mallick, M., Kumar, A., Tamboli, N., Kulkarni, A. B., Sati, P., \& Devi, V. Study on drag coefficient for the flow past a cylinder. International Journal of Civil Engineering Research 2014;5(4): 301-306.

[3] Nelwan, K. S. V., Balamba, S., \& Sarajar, A. N. Analisis Kelelahan Struktur Pada Tiang Pancang Di Dermaga Belang Dengan Metode Fracture Mechanics. TEKNO 2015;13(63).

[4] Gad-el-Hak, M. Flow control: passive, active, and reactive flow management. cambridge university Press. 2006.

[5] Akbiyık, H., Akansu, Y. E., \& Yavuz, H. Active control of flow around a circular cylinder by using intermittent DBD plasma actuators. Flow Measurement and Instrumentation 2017;53:215-220.

[6] Moreau, E. Airflow control by non-thermal plasma actuators. Journal of Physics D: Applied Physics 2007;40(3): 605.

[7] Tsutsui, T., \& Igarashi, T. Drag reduction of a circular cylinder in an air-stream. Journal of Wind Engineering and Industrial Aerodynamics 2002;90(4), 527-541.

[8] Triyogi, Y., Suprayogi, D., \& Spirda, E. Reducing the drag on a circular cylinder by upstream installation of an I-type bluff body as passive control. Proceedings of the Institution of Mechanical Engineers, Part C: Journal of Mechanical Engineering Science 2009;223(10): 2291-2296.

[9] Incropera, F. P., Lavine, A. S., Bergman, T. L., \& DeWitt, D. P. Fundamentals of heat and mass transfer. Wiley. 2007.

[10] Sosa, R., D’Adamo, J., \& Artana, G. Circular cylinder drag reduction by threeelectrode plasma actuators. In Journal of Physics: Conference Series 2015; Vol. 166: 12015.

[11] Tabatabaeian, S., Mirzaei, M., Sadighzadeh, A., Damideh, V., \& Shadaram, A. Experimental investigation of the effects of various plasma actuator configurations on lift and drag coefficients of a circular cylinder including the effects of electrodes. Chinese Journal of Aeronautics 2012;25(3): 311-324.

[12] Vernet, J. A., Örlü, R., \& Alfredsson, P. H. Separation control by means of plasma actuation on a half cylinder approached by a turbulent boundary layer. Journal of Wind Engineering and Industrial Aerodynamics 2015;145: 318-326. 
[13] Harinaldi, Budiarso, \& Julian, J. The effect of plasma actuator on the depreciation of the aerodynamic drag on box model. In AIP Conference Proceedings 2016; Vol. 1737:40004.

[14] Norouzi, M., Pooladi, M.A. and Mahmoudi, M.. Numerical Investigation of Drag Reduction in a Class 5 Medium Duty Truck. Journal of Mechanical Engineering and Sciences 2016;10:2387-400.

[15] Hussin, W.N.W., Harun, F.N., Mohd, M.H. and Rahman, M.A.A. Analytical Modelling Prediction by Using Wake Oscillator Model for Vortex-Induced Vibrations. Journal of Mechanical Engineering and Sciences 2017;11(4):31163128.

[16] Yaakub, M.F., Wahab, A.A., Abdullah, A., Mohd, N.A.R. and Shamsuddin, S.S.. Aerodynamic Prediction of Helicopter Rotor in Forward Flight Using Blade Element Theory. Journal of Mechanical Engineering and Sciences 2017;11(2):2711-2722.

[17] Reda, E., Zulkifli, R. and Harun, Z.. Large Eddy Simulation of Wind Flow Through An Urban Environment in Its Full-Scale Wind Tunnel Models. Journal of Mechanical Engineering and Sciences 2017;11(2):2665-2678.

[18] Reda, E., Zulkifli, R. and Harun, Z.. Towards Developing An Idealised City Model With Realistic Aerodynamic Features. Journal of Mechanical Engineering and Sciences 2017;11(4):2979-2992.

[19] James, J., Harinaldi, H. and Budiarso, B. The effect of plasma actuator placement on drag coefficient reduction of Ahmed body as an aerodynamic model. Int $\mathbf{J}$ Technol. 2017; 7:306-313.

[20] Julian, J., Harinaldi, Budiarso, Wang, C.C. and Chern, M.J.. Effect of plasma actuator in boundary layer on flat plate model with turbulent promoter. Proceedings of the Institution of Mechanical Engineers Part G: Journal of Aerospace Engineering. 2017:0954410017727301.

[21] J. Julian et all, Review Flow Control on A Squareback Model, International Review of Aerospace Engineering (IREASE) 2017; 10(4) 